\title{
Temporal comparator rules and responding in multiple schedules
}

\author{
LYNN ARONSON \\ Columbia University, New York, New York \\ PETER D. BALSAM \\ Barnard College of Columbia University, New York, New York \\ and \\ JOHN GIBBON \\ N.Y.S. Psychiatric Institute and Columbia University, New York, New York
}

\begin{abstract}
Three response rules for explaining the role of temporal factors in the control of responding were examined. These were the cycle-to-trial comparator rule from scalar expectancy theory (SET; Gibbon \& Balsam, 1981), the "deletion" comparator rule proposed by Cooper, Aronson, Balsam, and Gibbon (1990), and a "bad/good" comparator rule-a type of ITI-to-trial comparator. Two of these rules were designed to explain the acquisition of responding in simple associative learning paradigms (i.e., autoshaping). Here, their generality as predictors of response levels in responsedependent multiple schedules was examined. SET's overall cycle-to-trial comparator rule was the best predictor of the pattern of responding. Contrary to previous findings regarding contrast in multiple schedules, which show greater contrast with shorter component durations, there was no effect of absolute component duration. As predicted by SET, relative, not absolute, component durations controlled response levels.
\end{abstract}

The importance of temporal factors in the control of responding has been acknowledged for many years. A clear understanding of these factors can only come from an examination of their effects in a variety of conditioning paradigms. One major theory proposed to explain the role of temporal factors in Pavlovian conditioning was Gibbon and Balsam's (1981) scalar expectancy theory (SET). The generality of this theory would be severely limited if it could not also account for the influence of temporal factors in other conditioning paradigms. Here, we examine the applicability of SET, as well as two modifications of SET, to performance on response-dependent multiple schedules.

According to SET, responding depends on a comparison of the average wait for reinforcement in a signal (trial wait) with the average wait for reinforcement in the overall context in which that signal is embedded (cycle wait). When the ratio of cycle-to-trial waits exceeds a critical value, responding occurs to the signal. Gibbon and Bal-

This report is based on a thesis submitted by the first author to Columbia University in partial fulfillment of the requirements for the master's degree. This research was supported by National Institute of Mental Health Grant MH41649 to J. G. The authors would like to thank Raymond Garcia and Rachel Fromholtz for their assistance in conducting the experiments. We also thank Lee D. Cooper for his helpful comments in all phases of this research and Warren H. Meck and Herbert S. Terrace for their comments on an earlier version of the manuscript. Correspondence regarding this article should be sent to L. Aronson, Department of Biopsychology, Unit 50, New York State Psychiatric Institute, 722 West 168th St., New York, NY 10032. sam place the critical value at a ratio of $2: 1$. This overall cycle-to-trial comparator rule easily explains the trial spacing effect (Gibbon, Baldock, Locurto, Gold, \& Terrace, 1977; Terrace, Gibbon, Farrell, \& Baldock, 1975; see Gibbon \& Balsam, 1981, and Jenkins, Barnes, \& Barrera, 1981, for reviews), as well as the finding that the number of reinforcements to acquisition is approximately equal, regardless of the percentage of trials that are reinforced (Gibbon, Farrell, Locurto, Duncan, \& Terrace, 1980; Williams, 1981b).

SET's overall cycle-to-trial comparator rule can also account for both the lack of acquisition (Durlach, 1983; Gamzu \& Williams, 1973; Rescorla, 1968) and the loss of responding (Gamzu \& Schwartz, 1973; Lindblom \& Jenkins, 1981; Rescorla, 1989) in random control procedures. In the random control (or nondifferential) procedure, the cycle-to-trial ratio is $1: 1$ because reinforcement is presented with an equal probability both inside and outside of the signal, meaning that the average wait for food in the cue is equal to the average wait for food overall.

However, the SET cycle-to-trial comparator rule cannot account for a series of recent findings in which nondifferential procedures were used that showed evidence of response acquisition. These results led Cooper, Aronson, Balsam, and Gibbon (1990) to propose a modification of SET's original comparator rule, which they call the deletion comparator rule. The crucial findings that led to this modification showed that when stimuli are arranged so that a discriminable period of nonreinforcement exists in an otherwise nondifferential procedure, respond- 
ing may emerge. These findings have come from both the autoshaping and multiple-schedule paradigms (Brandon, 1984; Cooper et al., 1990; Durlach, 1983; Farley, 1980; Goddard \& Jenkins, 1987; Marcucella, 1976).

Farley (1980, Experiment 1; see also Brandon, 1984) examined maintained keypecking in pigeons trained on a three-cue multiple schedule. Initially, reinforcement was delivered at the same rate in all three components by using a response-independent, variable-time 60-sec (VT 60) schedule. There was little keypecking in this nondifferential procedure. Reinforcement was then removed from one VT 60 component and added to another; this created a component that was reinforced at a higher rate (VT 30) and a component that signaled nonreinforcement (extinction). In terms of the third, unchanged component, this procedure was still a nondifferential condition, with the same rate of reinforcement in the presence and absence of the cue. Overall, reinforcement was still presented at an average of every $60 \mathrm{sec}$. Responding was evoked, however, by the two reinforced cues using this procedure.

The creation of a discriminable period of nonreinforcement in an otherwise nondifferential procedure can also be achieved by the addition of another stimulus that "signals" the reinforcers that occur outside the target cue. Marcucella (1976) exposed pigeons to a two-component multiple schedule in which both components (e.g., red and green keylights) signaled equal variable-interval (VI) schedules. One component was then changed to a signaled VI schedule, in which a cue was added (a triangle was superimposed on the red keylight), which signaled the availability of reinforcers in that component. An increase in responding (positive contrast) occurred in the unchanged target component. The addition of a cue for reinforcement created an explicit cue for nonreinforcement. The reinforcement signal (the triangle) changed the twocomponent multiple schedule to a three-component multiple schedule with an extinction component (the red keylight). Additionally, Marcucella found that when only $50 \%$ of the foods in the changed component were signaled, there was no positive contrast. In this case, there was no cue for nonreinforcement because the component cue (red) was occasionally reinforced in the absence of the signal (see also Jenkins \& Lambos, 1983, Experiment 1, Group R.G.).

Using an autoshaping paradigm, Durlach (1983) showed acquisition of responding to a target $\mathrm{CS}$ in a random control procedure when the non-CS reinforcers were signaled by a second CS. As in Marcucella's (1976) study, the addition of a cue signaling the added reinforcers created an explicit cue for nonreinforcement (see also Goddard \& Jenkins, 1987).

SET's overall cycle-to-trial comparator rule cannot account for the results from any of these "signaling" procedures. According to SET, the fact that reinforcers outside the target cue are signaled should not affect responding to the target, because signaling does not change the overall cycle wait time; thus, cycle-to-trial ratios are unaffected and are still equal to 1 in these procedures. Contrary to this explanation, the studies cited above clearly showed that when cues are arranged so that the nontarget reinforcers are signaled and a discriminable period of nonreinforcement exists, responding can emerge in an otherwise nondifferential procedure.

Cooper et al.'s (1990) modification of the SET overall cycle-to-trial comparator rule was designed to accommodate the results from signaled random control procedures. According to this view, which we call the "deletion" $\mathrm{C} / \mathrm{T}$ comparator rule, learning about different signals is more or less independent. In other words, reinforcement in one cue should not affect responding in a second cue, unless the cues are presented as a compound. This makes the source of non-CS reinforcement in the nondifferential procedures crucial. If these extra reinforcers are signaled by a second cue, they will no longer affect responding in the target cue. According to the deletion comparator rule, other cues for reinforcement, and their reinforcers, are deleted or removed from the cycle against which the target cue is compared. Thus, a procedure like the one used by Durlach (1983), in which the extra USs are preceded by a brief signal, becomes analogous to a standard conditioning paradigm in terms of the target cue. The extra reinforcers and their signals are "deleted" and the target cue is compared with a cycle that includes only the target and nonreinforced time. The deletion comparator rule also accounts for Farley's (1980) findings.

Although the deletion comparator rule successfully explains the results in signaled random control procedures, another possible comparator rule can also account for these results. Furthermore, the experiments reported thus far cannot differentiate between the deletion comparator rule and this other comparator rule, which we call the "bad/good" comparator rule. This view is similar to deletion in that it proposes that cues are independent and that reinforcers in one cue should not affect learning about a second cue. It differs from the deletion comparator rule in that it abandons the notions of a cycle wait and of a ratio comparison of cycle-to-trial waits. The bad/good comparator rule is similar in spirit to the relative waiting time theory proposed by Jenkins et al. (1981). Their view is similar to SET, but is couched in terms of the wait in the CS being compared with the wait in the background, outside the CS (rather that in an overall cycle).

The bad/good comparator rule states that an animal compares the average extinction time (the "bad" wait) with the average wait for reinforcement when it is in the cue (the "good" wait). Basically, the claim is that the comparison is between the average wait to get into the good cue and the average wait for reinforcers once there. Consider, for example, a two-cue multiple schedule, with VI 30-sec and extinction components. Component durations are always $2 \mathrm{~min}$. This makes the average bad wait $2 \mathrm{~min}$; the average good wait is $30 \mathrm{sec}$. The bad/good ratio is therefore $4: 1$. For the sake of simplicity, we are assuming that the response threshold is around $1: 1$, which corresponds to the 2:1 threshold in SET, so we expect responding in this procedure. In a standard nondifferential procedure, there is no "bad" time because there is no cue for nonreinforcement. In that case, this view could be extended to propose that the target cue would be com- 
pared with other concurrently presented cues or to other cues that surround the target CS. In either case, there would be a prediction of no responding. The bad/good comparator rule correctly predicts responding in signaled random control procedures because the signaling procedure creates a "bad" period in the intertrial interval (ITI). Note that if the "bad" wait is too short, responding will not occur (see Cooper, Aronson, Balsam, \& Gibbon, 1988a, 1988b, 1990; Durlach, 1989; Robbins \& Rescorla, 1989).

The deletion and bad/good comparator rules are very similar; the difference is that the deletion rule uses a cycleto-trial comparison, whereas the bad/good rule uses what is basically an ITI-to-trial comparison. The two comparator rules do, however, make divergent predictions about the effects of certain manipulations. One is the effect of increasing target time in the session. According to the deletion comparator rule, increasing target time will reduce the average wait in the cycle and thus lower the cycle-totrial ratio. The bad/good comparator rule, however, is insensitive to the amount of target time in the session as long as the rate of reinforcement in the target is constant. If the target is reinforced on an average of $30 \mathrm{sec}$ and there is an average extinction time of $2 \mathrm{~min}$, the bad/good ratio will be $4: 1$, regardless of whether the target cue is presented for $30 \mathrm{sec}$ or $2 \mathrm{~min}$. Thus, to differentiate between the deletion and bad/good comparator rules, the amount of time that the target cue is present relative to nonreinforced time must be manipulated independently of the reinforcement rate in the target.

The present experiment was designed to differentiate the deletion and bad/good comparator rules and also to provide further tests of the generality of the SET overall cycle-to-trial comparator rule in an operant procedure. The principle advantage of testing these hypotheses with a response-dependent schedule was that this procedure ensured that a nonzero floor level of responding was evident in all of the experimental conditions. We were therefore able to examine both the facilitative and suppressive effects of various temporal manipulations on response levels relative to baseline. The recoverable baseline level of responding that a response-dependent schedule provides is crucial for a full examination of these effects, because of the known historical effects of nondifferential procedures in response-independent procedures such as autoshaping. Animals exposed to response-independent random control procedures exhibit a lasting suppressive effect on responding (Baker \& MacKintosh, 1979; Balsam, Aronson, \& Scopatz, 1987; Tomie, 1981, 1985; Tomie, Murphy, Fath, \& Jackson, 1980). The use of response-dependent schedules avoids that problem. It allows an examination of the effects of temporal manipulations using a withinsubject design. These types of temporal manipulations are known to have an effect on response acquisition rates when between-subject comparisons are used. Here, we can test the generality of these temporal effects by examining changes in response levels within subjects.

Specifically, we used a multiple schedule with two or three components to examine which comparator rule best predicts changes in responding. A target cue component and an extinction component were always present. We also examined the effect on target responding of the addition of reinforcers to the session that were signaled by either a third cue (referred to as the "other VI" cue) or the target itself, as well as the effect of changing the duration of the extinction component.

The design of the experiment is shown schematically in Figure 1. The specific conditions and the ratio values for the target cue, according to each comparator rule for each condition, are shown in Table 1 . The same set of conditions was presented twice, once with absolute component durations that were long (a range of 1-6 min, shown in Table 1) and once with absolute component durations that were short (a range of 6-36 sec, also shown in Table 1). The reasons for this manipulation are discussed below. Note that the comparator ratio values for each condition are the same for both the minute- and second-range versions of a condition. For clarity, we will refer to conditions by their minute-range labels only.

In the baseline condition, a short target component was presented with a long extinction component. This was the 1-0-6 minute-range condition, consisting of a 1-min target component, a zero or absent other VI component, and a 6-min extinction component. In this initial condition, all three temporal comparator rules predicted high levels of responding.

In the next condition, another source of reinforcement was added to the session in the form of a third schedule component. This manipulation corresponded to the 1-5-6

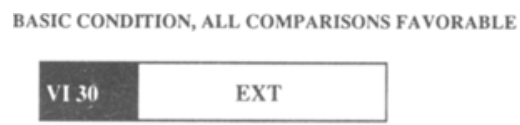

ADD OTHER SOURCE OF REINFORCEMENT

\begin{tabular}{|l|l|l|}
\hline VI 30 & OTHER VI 30 & EXT \\
\hline
\end{tabular}

ADD REINFORCEMENT TIME IN THE TARGET CUE

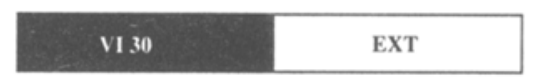

ADD REINFORCEMENT TIME IN TARGET AND IN ANOTHER CUE

\begin{tabular}{|l|l|l|}
\hline VI 30 & OTHER VI 30 & EXT \\
\hline
\end{tabular}

REMOVE EXTINCTION TIME

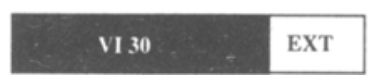

Figure 1. The schematic design of the experiment. A three-cue multiple schedule was used. The black areas indicate the target cue component, which was presented in all of the conditions. The gray areas depict a second reinforced cue component, which was presented in two of the conditions. The white areas depict the extinction cue component, which was presented in all of the conditions. See text for further details. 
Table 1

Experimental Conditions

\begin{tabular}{|c|c|c|c|c|c|}
\hline \multicolumn{3}{|c|}{ Component } & \multicolumn{3}{|c|}{ Ratios for Target Cue } \\
\hline $\begin{array}{l}\text { Target } \\
\text { VI } 30 \\
\end{array}$ & $\begin{array}{l}\text { Other } \\
\text { VI } 30\end{array}$ & Extinction & $\begin{array}{c}\text { Overall } \\
\text { C/T Ratio }\end{array}$ & $\begin{array}{c}\text { Deletion } \\
\text { C/T Ratio } \\
\end{array}$ & $\begin{array}{c}\mathrm{Bad} / \mathrm{Good} \\
\text { Ratio }\end{array}$ \\
\hline $\begin{array}{l}\mathbf{1}^{\prime} \\
6^{\prime \prime}\end{array}$ & $\begin{array}{l}0^{\prime} \\
0^{\prime \prime}\end{array}$ & $\begin{array}{c}6^{\prime} \\
36^{\prime \prime}\end{array}$ & [7:1] & {$[7: 1]$} & {$[12: 1\rceil$} \\
\hline $\begin{array}{l}1^{\prime} \\
6^{\prime \prime}\end{array}$ & $\begin{array}{c}5^{\prime} \\
30^{\prime \prime}\end{array}$ & $\begin{array}{c}6^{\prime} \\
36^{\prime \prime}\end{array}$ & {$[2: 1]$} & (7:1 & $12: 1$ \\
\hline $\begin{array}{c}6^{\prime} \\
36^{\prime \prime}\end{array}$ & $\begin{array}{l}\mathbf{0}^{\prime} \\
0^{\prime \prime}\end{array}$ & $\begin{array}{c}6^{\prime} \\
36^{\prime \prime}\end{array}$ & {$[2: 1$} & $2: 1]$ & $12: 1$ \\
\hline $\begin{array}{c}6^{\prime} \\
36^{\prime \prime}\end{array}$ & $\begin{array}{c}6^{\prime} \\
36^{\prime \prime}\end{array}$ & $\begin{array}{c}6^{\prime} \\
36^{\prime \prime}\end{array}$ & $3: 2]$ & [2:1] & 12:1 \\
\hline $\begin{array}{c}6^{\prime} \\
36^{\prime \prime}\end{array}$ & $\begin{array}{l}\mathbf{0}^{\prime} \\
O^{\prime \prime}\end{array}$ & $\begin{array}{l}1^{\prime} \\
6^{\prime \prime}\end{array}$ & [7:6] & {$[7: 6]$} & {$[2: 1]$} \\
\hline
\end{tabular}

Note-The durations for the three components in each condition are listed on the left half of the table. A zero duration means that the component was not presented in that condition. Minute-range conditions are shown in bold type. The corresponding second-range conditions are shown below them in italics. Ratio values for the target cue according to each comparator rule are shown on the right. Conditions grouped by brackets were predicted to produce similar levels of responding according to that comparator. Ratios below 2:1 were not expected to promote excitatory strength above a floor level of responding associated with the VI.

condition. In terms of the target component, reinforcers are added but are signaled by another cue. Therefore, this condition provided a test of the deletion and bad/good comparator rules relative to the overall SET comparator. Both the deletion and bad/good comparator rules claim that the addition of the other VI cue should not affect responding in the target, because that cue is not involved in target cue comparisons. As seen in Table 1, the ratio values for the target cue do not change in this condition for these comparator rules. However, the overall comparator rule predicted that target responding would decrease in this condition because the addition of reinforcers to the session reduced the overall cycle wait. This is seen in the reduced overall $\mathrm{C} / \mathrm{T}$ ratio for the target cue in this condition.

The third line of Figure 1 depicts a condition in which the same amount of reinforced time was added to the session, as in the second line, but instead of being signaled by the other VI cue it is signaled by the target cue itself. This corresponded to the 6-0-6 condition. Here, the deletion comparator rule predicted a decrement in responding relative to the baseline condition, because this additional reinforced time cannot be deleted from the target comparison. Thus, cycle time is decreased and the cycle-totrial ratio is lowered. (Note that when only one reinforced cue is present, the deletion comparator rule is identical to the overall SET comparator rule because there is nothing to "delete.") The bad/good comparator rule however, predicted no decrement in responding in the third condition relative to baseline. According to the bad/good rule, this is because the average wait in the trial, which is unaffected by the actual amount of time that the trial is present, is crucial.
In the next condition, 6-6-6, reinforced time was added in both the target and the other reinforced cue. This provided a test of the deletion and bad/good comparator rules relative to the 6-0-6 condition. According to these comparator rules, this further addition of reinforcers to the session should have no effect on responding to the target cue. According to the overall comparator rule, this manipulation further reduces the cycle wait and therefore reduces the $\mathrm{C} / \mathrm{T}$ ratio even further. In fact, the overall $\mathrm{C} / \mathrm{T}$ ratio for this condition is below the threshold value of 2 , so according to this comparator rule, responding should be at the floor level necessary to obtain reinforcers on the VI schedule.

In all of the conditions discussed so far, the bad/good comparator value for the target cue remained high at 12:1. This is because, regardless of the amount of reinforced time in the session, the rate of reinforcement in the target had not changed, so the average wait for food in the target also had not changed (on a VI 30, the "good" wait was $30 \mathrm{sec}$ ). Similarly, in all of the conditions, the duration of the extinction component remained stable at $6 \mathrm{~min}$ (the "bad" wait). In the final condition, shown schematically at the bottom of Figure 1, the duration of the extinction component was reduced. This manipulation corresponded to the 6-0-1 condition. Here, the bad/good comparator rule predicted a decrement in responding because the "bad" wait was shorter, reducing the bad-wait to good-wait ratio. This is the only condition in which the bad/good comparator rule predicted a decrement in responding relative to baseline. The deletion and overall comparator rules both predicted further decrements in response levels to the target cue in this condition, because the reduction of extinction time lowers the cycle time.

Overall, the purpose of the experiment was to determine whether responding to a target cue would be sensitive to the addition of extra reinforcers when they were signaled by a different cue, or to changes in the duration of an extinction component. The key question was which comparator rule would best predict the pattern of responding to the target cue. In Table 1, the conditions expected to produce similar levels of responding according to each comparator rule are grouped by brackets. The overall $\mathrm{C} / \mathrm{T}$ comparator rule predicted three levels of responding - a high level of responding in Condition 1-0-6, a moderate level of responding in Conditions 1-5-6 and 6-0-6, and a low level of responding in Conditions 6-6-6 and 6-0-1. The deletion $\mathrm{C} / \mathrm{T}$ comparator rule also predicted three levels of responding, but with a different pattern of conditions. It predicted a high level of responding to Conditions 1-0-6 and 1-5-6 because both have a short target component. Similarly, it predicted a moderate level of responding in the 6-0-6 and 6-6-6 conditions. Finally, it predicted a low level of responding in the 6-0-1 condition. The bad/good comparator rule predicted a pattern with only two levels of responding. According to this view, all of the conditions with a long extinction component (1-0-6, 1-5-6, 6-0-6, and 6-6-6) should produce high levels of responding, whereas the condition with a short extinction component (6-0-1) should produce a low level of responding. 
The minute-range versus second-range manipulation was done for several reasons. First, it allowed a clear comparison with multiple-schedule results such as Farley's (1980), in which long-duration cues were used, as well as with autoshaping results such as Durlach's (1983), in which short-duration cues were used. Second, previous research using multiple schedules suggests that animals are more sensitive to short component durations and the more frequent alternations between components that occur when short components are used (see Williams, 1983, 1989 for reviews). Third, and most important for our purposes, the minute-range versus second-range manipulation tests an assumption of all three comparator rulesthat ratios of times, and not absolute durations, control responding.

\section{METHOD}

\section{Subjects and Apparatus}

The subjects were 6 White Carneaux pigeons obtained from the Palmetto Pigeon Plant. The subjects had all been previously autoshaped to the keylight stimuli used in this experiment and had experience with multiple schedules. They were housed individually with free access to water. Throughout the experiment, the pigeons were maintained at $80 \%$ of their free-feeding weights.

Three identical experimental chambers were used. Each was a standard BRS/LVE pigeon conditioning chamber, with internal dimensions measuring $34 \mathrm{~cm}$ long $\times 34 \mathrm{~cm}$ wide $\times 30 \mathrm{~cm}$ high. An aluminum wall in each chamber contained three response keys, each $3.5 \mathrm{~cm}$ in diameter. The center of each response key was $25 \mathrm{~cm}$ above the wire-mesh floor of the chamber. A $5 \times 5 \mathrm{~cm}$ food magazine was located $10 \mathrm{~cm}$ above the floor at the center of this wall, below the center response key. Only the center response key was used in this experiment.

Illumination was provided by a $15-\mathrm{W}$ houselight, mounted $30 \mathrm{~cm}$ above the floor in the center of the aluminum wall. The houselight was on continuously except during hopper activation, when a hopper light provided the only illumination in the chamber.

The keylight stimuli were generated by an IEE projection device (BRS/LVE Model IC-901/111-06) located behind the center key. Three keylight stimuli were used: a red light, a green light, and a white light.

The chambers were equipped with an externally mounted fan, which provided masking noise and ventilation. All of the cham- bers were housed in a sound-attenuating room. The experimental manipulations and data collection were controlled by a microcomputer system (Cooper, Garcia, \& Gibbon, 1988).

\section{Procedure}

Minute-range conditions. The subjects were exposed to a series of five different multiple schedules, which had two or three components (see Table 1). The durations of the components varied independently within the range of 1-6 min.

Red, green, and white keylights were used as stimuli. Specific assignment of colors to the different schedule components was counterbalanced across subjects. For each subject, the target cue signaled a VI 30 -sec schedule, as did the cue we called the "other" cue, meaning the other reinforced cue. The third cue signaled extinction. The target cue and extinction cue components were always presented. The other reinforced cue component was presented in two of the five conditions. All keylight stimuli were presented on the center response key.

The conditions are referred to by three numbers, indicating the duration in minutes of the target cue, other reinforced cue, and extinction cue components, respectively. For example, the 1-0-6 condition involved a 1 -min target component, no other cue component, and a 6-min extinction component. The details of the experimental sessions for each of the five minute-range conditions are shown in Table 2. Note that the session durations were designed to equalize the number of reinforcers in the target cue in all conditions except 1-5-6, which was designed so that the overall number of reinforcers equaled that in the 6-0-6 condition.

The VI 30 schedules were programmed by having reinforcements set up with a probability of .2 after every $6 \mathrm{sec}$ within the component. The first peck after a reinforcer was set up caused delivery of the reinforcer. Reinforcers were a 3-sec hopper presentation of mixed grain. All keylight stimuli and the houselight were turned off during hopper activation, when a hopper light provided illumination.

The order of component presentations was random within a session, with the following constraints. In the 1-0-6 condition, the same component could not occur more than twice in a row; in all other conditions, the same component could not follow itself.

The subjects were exposed to each condition twice in a random order, which was different for each subject. Each exposure was for five sessions; sessions occurred once a day, 5 days a week.

Second-range conditions. Next, the subjects were exposed to the same five conditions except with the absolute component durations reduced by a factor of 10 . These second-range conditions are listed in Table 2. All the details of the experimental sessions were the same for the second-range conditions and for the corresponding

Table 2

Details of the Experimental Conditions

\begin{tabular}{lccccc}
\hline $\begin{array}{l}\text { Condition } \\
\text { (T-0-E) }\end{array}$ & $\begin{array}{c}\text { Session } \\
\text { Length } \\
\text { (in Minutes) }\end{array}$ & $\begin{array}{c}\text { Number of } \\
\text { Presentations } \\
\text { of Each } \\
\text { Component }\end{array}$ & $\begin{array}{c}\text { Target } \\
\text { Reinforcers }\end{array}$ & $\begin{array}{c}\text { Other Cue } \\
\text { Reinforcers }\end{array}$ & $\begin{array}{c}\text { Total } \\
\text { Reinforcers }\end{array}$ \\
\hline $\begin{array}{l}1-0-6 \\
6-0-36\end{array}$ & 84 & 12 & 24 & 0 & 24 \\
1-5-6 & 24 & 120 & & & \\
$6-30-36$ & 20 & 20 & 4 & 20 & 24 \\
$6-0-6$ & 24 & 2 & 24 & 0 & 24 \\
$36-0-36$ & & 20 & & & \\
$6-6-6$ & 36 & 2 & 24 & 24 & 48 \\
$36-36-36$ & & 20 & & & \\
$6-0-1$ & 14 & 2 & 24 & 0 & 24 \\
$36-0-6$ & & 20 & & & \\
\hline
\end{tabular}

Note-T-O-E = target VI 30-other VI 30-extinction. The minute-range conditions are shown in bold type. The second-range conditions are shown in italics. 
minute-range conditions, except the number of presentations of each component. Component orders within a session were random, with the constraint that the same component could not occur more than twice in a row in all conditions.

In this phase, the VI 30 schedules were programmed by having reinforcement set up with a probability of .067 after every 2 sec within a component.

The subjects were exposed to each condition once for 1 week. Two random orders of exposure to the different conditions were used, with 3 subjects receiving each order.

\section{RESULTS}

The daily response rates for representative Subject 4670 , during the minute-range portion of the experiment, are shown in Figure 2. Three things were characteristic for all of the subjects. First, the level of responding to the extinction cue was very low throughout the experiment. Second, the changes in response rate accompanying a new condition generally occurred in the first session of the change. For example, both transitions to the 1-0-6 condition showed immediate response-rate increases to the target cue. Third, when the other VI 30 cue was presented, response rates for the two reinforced cues were similar. This was the case in both the 1-5-6 and 6-6-6 conditions. The average response rates of all the subjects to the target and other VI cues, respectively, were 59.42 and 53.53 for the 1-5-6 condition, and 50.16 and 48.71 for the 6-6-6 condition. A two-way analysis of variance (ANOVA) with condition and cue as factors showed a main effect of conditions $[F(1,20)=11.88, p<.01]$, but no effect of cue $[F(1,20)=2.89$, n.s. $]$. The condition $\times$ cue interaction was not significant $[F(1,20)=$ 1.125 , n.s.].

The subjects were exposed to each minute-range condition twice. Response rates during the two exposures to each condition were similar. A two-way ANOVA with condition and exposure as factors revealed a significant effect of conditions $[F(4,50)=18.77, p<.01]$, but no effect of exposure $[F(1,50)=.814$, n.s. $]$. The condition $\times$ exposure interaction was also not significant $[F(4,50)=$ .722 , n.s.].

Because there was no difference between the two exposures to the minutes conditions and there was only one exposure to each second-range condition, only data from the second of the minute-range exposures was used in subsequent analyses. The second exposure was chosen because it occurred closer in time to the presentation of the second-range conditions.

In the second-range conditions, as in the minute-range conditions, there was no difference in response levels to the target and other VI cues when both were presented. The average response rates to the two cues were 69.13 (target cue) and 58.42 (other VI cue) in the 6-30-36 condition, and 42.92 (target cue) and 44.19 (other VI cue) in the 36-36-36 condition. A two-way ANOVA with condition and cue as factors showed no effect of cue $[F(1,20)=.377$, n.s. $]$, but did show a significant effect of condition $[F(1,20)=6.91, p<.017]$. The condition

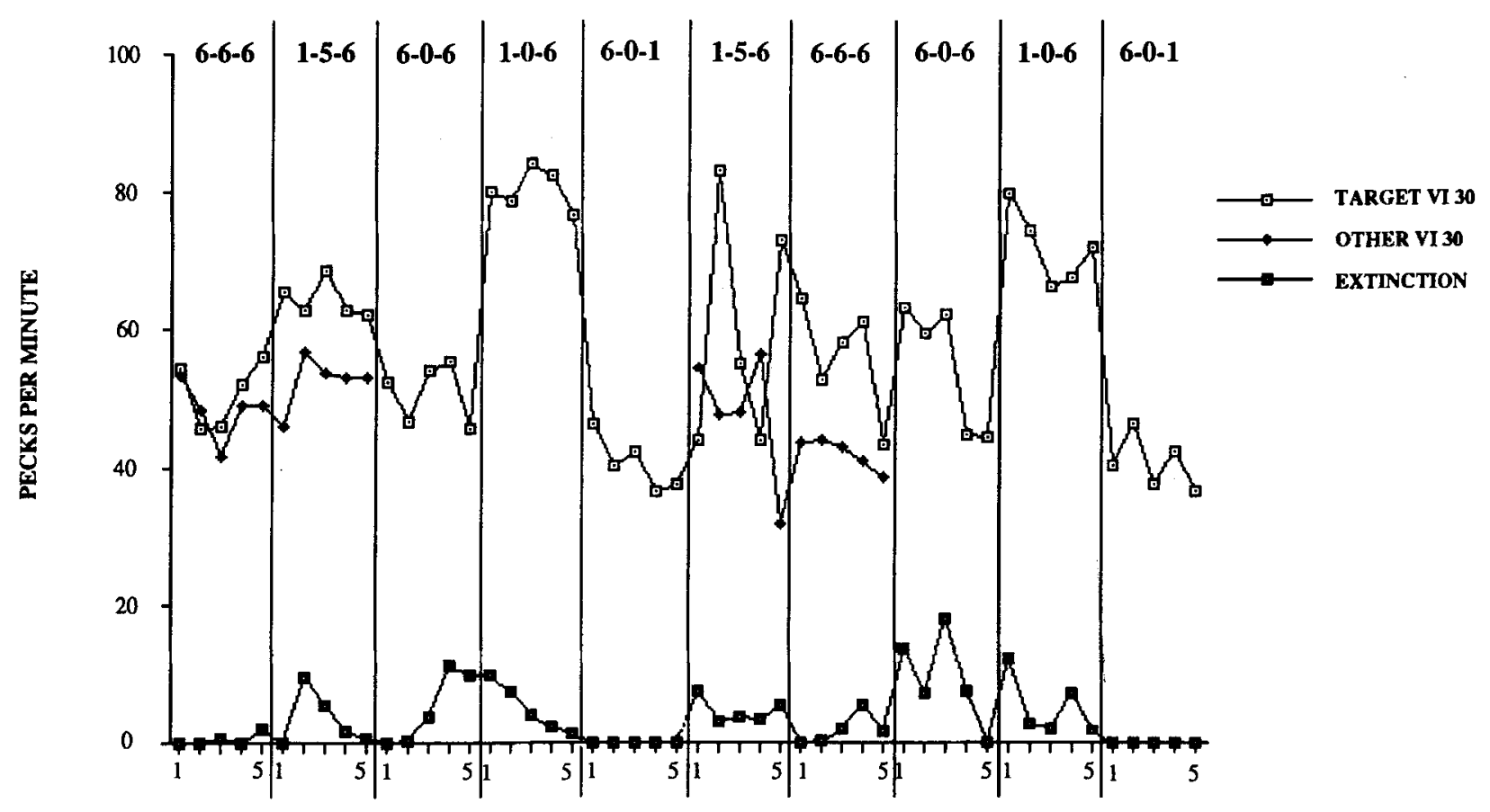

SESSION

Figure 2. Response rates for Subject $\mathbf{4 6 7 0}$ during each session of the minute-range portion of the experiment. Conditions are listed across the top of the figure, 
$\times$ cue interaction was, again, not significant $[F(1,20)=$ .606 , n.s.].

The average response rates to the target cue for all of the second-range conditions and for the final exposure to the minute-range conditions are shown in Figure 3. The ratio values for the target cue according to each comparator rule are listed below the figure. All of the comparator rules assume that ratios of times, not absolute durations, control responding. This, in fact, was the case here. Planned comparisons showed no overall difference between the minute- and second-range conditions $[t(50)=$ .0023 , n.s.]. A two-way ANOVA with condition and time (minutes vs. seconds) as factors showed no effect of the time variable $[F(1,50)=.016$, n.s. $]$, but did show a main effect of conditions $[F(4,50)=7.70, p<.01]$. The condition $\times$ time interaction was not significant $[F(4,50)=$ .543 , n.s.].

Because of the lack of difference between the minuteand second-range conditions, the data were pooled across the two ranges in further analyses.

A series of planned comparisons were done on the basis of the ratio values of the three comparator rules to determine which best predicted the obtained pattern of responding. The specific predictions of each comparator rule are based on the ratio values for the target cue in each condition listed in Table 1. Conditions expected to produce similar response levels according to each comparator rule are bracketed in the table. The first set of planned comparisons was based on the overall $\mathrm{C} / \mathrm{T}$ comparator rule. The conditions will be referred to by their minute-range labels only for ease of discussion, although all comparisons reflect pooling across minutes and seconds.
The overall $\mathrm{C} / \mathrm{T}$ rule's first prediction was that the conditions that had ratios below threshold, 6-6-6 and 6-0-1, would not be different, which was the case $[t(50)=$ .2336 , n.s.]. This result was not anticipated by either the deletion or the bad/good comparator rules, which predicted higher response rates in the 6-6-6 condition than in the 6-0-1 condition. The second prediction of the overall $C / T$ comparator was that the $1-5-6$ and $6-0-6$ conditions would show similar response rates because both had target $\mathrm{C} / \mathrm{T}$ ratios of 2 . These conditions were not different $[t(50)=1.0289$, n.s. $]$, as predicted by the overall $\mathrm{C} / \mathrm{T}$ comparator rule. This outcome is contrary to the deletion comparator rule, which predicted higher responding in the 1-5-6 condition. The data, in fact, lean in the direction opposite to the deletion comparator rule's prediction.

The overall comparator rule also predicted that the two sets of conditions (6-6-6 and 6-0-1 vs. $1-5-6$ and 6-6-6) would be different, which they were $[t(50)=3.731, p<$ $.01]$. Finally, the overall comparator rule predicted that the 1-0-6 condition, with a $\mathrm{C} / \mathrm{T}$ ratio of 7 , would show significantly higher responding than all of the other conditions. Because the conditions with $\mathrm{C} / \mathrm{Ts}$ equal to 2 (1-5-6 and 6-0-6) and those with C/Ts less than 2 (6-6-6 and 6-0-1) were different, they could not be pooled, and the 1-0-6 condition was compared with each of them separately. The 1-0-6 condition was different from the two conditions with $\mathrm{C} / \mathrm{T}$ ratios of $2[t(50)=4.7328, p<$ $.01]$. (Note that the bad/good comparator rule incorrectly predicted that these conditions would all show similar responding.) Of course, the 1-0-6 condition was also different from the two conditions with $\mathrm{C} / \mathrm{T}$ ratios below 2 $[t(50)=7.993, p<.01]$.

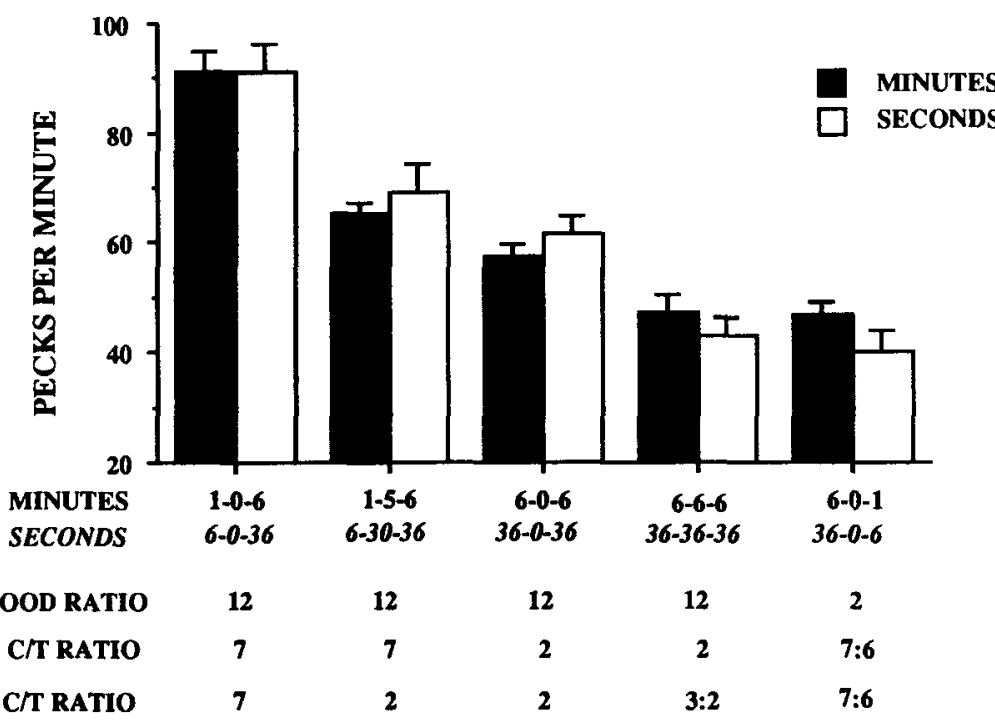

Figure 3. The average response rates in the target cue for all 6 subjects during all conditions in both the minute (dark bars) and second (open bars) ranges. Lines above the bars show standard errors. The ratios for the target cue for each condition according to each comparator are listed below the figure. Note that the ratio remains the same for both the minute- and secondrange versions of a condition. 
In summary, the planned comparisons indicated three general levels of responding-a high level for Condition 1-0-6, a moderate level for Conditions 1-5-6 and 6-0-6, and a low level for Conditions 6-6-6 and 6-0-1. All of the predictions of the overall $\mathrm{C} / \mathrm{T}$ comparator were supported.

The planned comparison analysis seems to rule out the bad/good comparator rule. It predicted that all the conditions except 6-0-1 would show similar response levels, but we have already shown that the 1-0-6 condition was different from the others and that the 6-6-6 and 6-0-1 conditions were not different.

Although the above comparisons showed some violations of the deletion comparator rule, its strongest predictions have not been specifically tested; that is, the predictions based on the notion that the addition of another cue for reinforcement should not affect responding in the target cue. Thus, the deletion comparator rule predicted that the 1-0-6 and 1-5-6 conditions would not be different in terms of target responding; neither would the 6-0-6 and 6-6-6 conditions. Neither of these predictions was supported. The 1-0-6 and $1-5-6$ conditions did differ $[t(50)=$ $3.315, p<.01]$, as did the 6-0-6 and 6-6-6 conditions $[t(50)=2.01, p<.01]$.

The obtained pattern of target responding was exactly that predicted by the overall $\mathrm{C} / \mathrm{T}$ comparator rule and cannot be accounted for by either the deletion or bad/good comparator rules. Furthermore, the fact the response rates to the other reinforced cue were not different from those to the target cue when both were presented is also explained by the overall $\mathrm{C} / \mathrm{T}$ comparator rule. Because the two cues were reinforced at the same rate, their ratios were identical according to the overall comparator rule.

\section{DISCUSSION}

Although it was predicted by the comparator rules, the failure to find a difference in response rates between the minute-range and second-range conditions is surprising. The common findings in the literature are that response rates are higher, and contrast effects are enhanced, by shorter component durations (see Williams, 1983, for a review). Researchers have found that when components are of equal length and vary together, absolute response rates are higher with shorter component durations (Shimp \& Wheatley, 1971; Williams, 1980). McSweeney (1982) examined contrast when a VI 2-min-VI 2-min schedule was changed to VI 2-EXT at a range of component durations. She found that contrast varied systematically with component durations ranging from $5 \mathrm{sec}$ to $8 \mathrm{~min}$, with contrast largest at the shortest durations.

On the other hand, Charman and Davison (1982) failed to find an effect of absolute component durations. They examined contrast effects over a range of reinforcement rates and component durations and found that the sensitivity to reinforcement-rate changes was the same over component durations ranging from $5 \mathrm{sec}$ to $2 \mathrm{~min}$. A key feature of their experiment was that the components were not of equal duration; one component was always five times longer than the other. Thus, as in some conditions in the present experiment, the durations of the different components were not equal. In both cases, when the relative durations of the components were constant, the absolute duration effect was not observed.

Williams (1989) suggested a possible explanation for these divergent findings on the effects of component durations. He pointed out that there are two opposing effects operating in any manipulation of component duration. Shorter durations of the more highly valued component lead to higher response rates in that component, whereas longer durations of the alternative component also lead to higher response rates in the more highly valued component. For example, in a VI-EXT schedule, if the duration of the VI component is held constant while the duration of the extinction component is varied, the response rate in the VI is higher the longer the extinction component (Ettinger \& Staddon, 1982; Wilton \& Clements, 1971). On the other hand, if the extinction component duration is held constant and the duration of the VI component is varied, the response rate is higher the shorter the VI component (Hinson, Malone, McNally, \& Rowe, 1978). Given these opposing effects, Williams (1989) pointed out that failures to find an effect of component duration may not be due to insensitivity to the component durations per se, but rather may be due to opposing effects. In this experiment, the extinction component was long relative to the target in most conditions, even when the absolute component durations were short. However, for this explanation to account for these results, in which a ratio effect is preserved over a wide range of absolute component durations, the opposing effects of extinction duration and CS duration would have to perfectly counterbalance each other across this range of component durations. This is highly unlikely. An alternative view is simply to appeal to a ratio mechanism to account for these effects.

The main finding of the present study is also surprising in that it contrasts previous research on signaled nondifferential procedures (e.g., Cooper et al., 1990; Durlach, 1983; Farley, 1980; Marcucella, 1976). In those studies, the overall rate of reinforcement was held constant but cues were added to signal reinforcers that occurred outside the target cue. The results in those studies clearly support a deletion comparator rule (see Cooper et al., 1990). Here, however, we did not find an analogous effect of signaling added reinforcers; instead, we showed that changes in the overall rate of reinforcement will affect responding to a target cue in a manner consistent with an overall $\mathrm{C} / \mathrm{T}$ comparator rule (Gibbon \& Balsam, 1981).

There are several possibilities for reconciliation. The most obvious is that the present experiment used VI schedules, and thus included a response requirement. Most of the cited research that supports the deletion comparator rule used response-independent procedures (although Marcucella used VI schedules). In those experiments, when temporal conditions were unfavorable, responding dropped out almost completely. Here, a floor level of re- 
sponding was present even under the most unfavorable conditions because of the VI response requirement. It is possible that the present experiment examined an issue that was fundamentally different from these other studies. Here, the question was what controls changes in levels of maintained responding. In the other studies (which supported the deletion comparator rule), the main issue was what controls the acquisition and emergence of responding or, simply, what controls whether or not responding occurs. During maintained responding, overall temporal factors may play a more important role in determining resonse levels, as they did here. In the studies designed to examine response acquisition, such as Durlach (1983) and Cooper et al. (1990), levels of maintained responding were not closely examined.

Yet another possibility to explain the difference between the present results and those of earlier studies is that local temporal effects may have played a crucial role in the early experiments, but were diminished here. By the terms local effect or local context we refer to the stimulus conditions directly surrounding (preceding or following) a target cue. For example, Farley (1980) used fixedcomponent orders in his experiment. Although the specific order of cues was not the same for all the subjects, they all had an extinction component in a consistent relationship either before or after the target cue. Thus, Farley provided a consistent local context for the target component. In the present experiment, the component orders were variable, making local comparisons less informative. This could have promoted the use of overall comparisons. In signaled random control procedures such as Durlach's (1983), local comparisons are also very consistent and therefore may be informative. Although cues are not presented in a fixed order in these procedures, there is a much higher proportion of nonreinforced time than anything else in the session. Because of this, most target cues will be embedded in a nonreinforced local context. Several studies point to the possibility that a consistent local context can overcome overall temporal effects (Farley, 1980; Reilly \& Schachtman, 1987; Schachtman \& Reilly, 1987; Williams, 1979, 1981a).

A final possible explanation for the inconsistencies between this study and the previous work supporting the deletion hypothesis is that the conditions necessary for the deletion comparator rule to operate may not have been met in this experiment. Here, the other reinforced cue was reinforced at the same rate as the target cue. It may be that for a cue to be "deletable," it must be reinforced at a different rate. In signaled random control procedures, the cover cue is reinforced $100 \%$ of the the time, whereas the target cue is partially reinforced-usually on only $20 \%-40 \%$ of its presentations. This differential rate may promote independent comparisons. Differential reinforcement rates were also present in Farley's (1980) procedure. To introduce an extinction component, Farley removed reinforcement from one component and added it to another, thus creating a component that was reinforced at a higher rate than the target component. In fact, all of the studies cited above that support the deletion compa- rator rule used different rates of reinforcement in the reinforced cues. It may be that differential reinforcement rate is one of the fundamental conditions required for the operation of a deletion comparator rule.

\section{REFERENCES}

BaKeR, A. G., \& MacKintosh, N. J. (1979). Excitatory and inhibitory conditioning following uncorrelated presentations of CS and UCS. Animal Learning \& Behavior, 5, 315-319.

Balsam, P. D., Aronson, L., \& Scopatz, R. (1987, November). Learning and performance effects of nondifferential CS/US presentation. Paper presented at the meeting of the Psychonomic Society, Seattle, WA.

Brandon, S. E. (1984). A test of the Wagner-Rescorla model's prediction of no response decrement in a nondifferential following a differential schedule of reinforcement. Animal Learning \& Behavior, $12,137-141$.

Charman, L., \& Davison, M. (1982). On the effects of component durations and component reinforcement rates in multiple schedules. Journal of the Experimental Analysis of Behavior, 37, 417-439.

Cooper, L. D., Aronson, L., Balsam, P. D., \& Gibbon, J. (1988a, April). Duration effects signaling intertrial USs in autoshaping. Paper presented at the meeting of the Eastern Psychological Association, Buffalo, NY.

Cooper, L. D., Aronson, L., Balsam, P. D., \& Gibbon, J. (1988b, November). A reexamination of contingency in Pavlovian conditioning. Multiple associations. Paper presented at the meeting of the Psychonomic Society, Chicago, IL.

Cooper, L. D., Aronson, L., Balsam, P. D., \& Gibbon, J. (1990). Duration of signals for intertrial reinforcement and nonreinforcement in random control procedures. Journal of Experimental Psychology: Animal Behavior Processes, 16, 14-26.

COOPER, L. D., Garcia, R., \& GibBon, J. (1988). The labtop Macintosh: An interface and communications software for experiment control of animal learning research. Behavior Research Methods, Instruments, \& Computers, 20, 88-92.

DURLACH, P. D. (1983). Effect of signaling intertrial unconditioned stimuli in autoshaping. Journal of Experimental Psychology: Animal Behavior Processes, 9, 374-389.

DuRLACH, P. D. (1989). Role of signals for unconditioned stimulus absence in the sensitivity of autoshaping to contingency. Journal of Experimental Psychology: Animal Behavior Processes, 15, 202-211.

ETTINGER, R.H., \& STADDON, J. E. R. (1982). Behavioral competition, component duration and multiple-schedule contrast. Behaviour Analysis Letters, 2, 31-38.

FarleY, J. (1980). Automaintenance, contrast and contingencies: Effects of local versus overall and prior versus impending reinforcement context. Learning \& Motivation, 11, 19-48.

Gamzu, E., \& SchWartz, B. (1973). The maintenance of key pecking by stimulus-contingent and response-independent food presentation. Journal of the Experimental Analysis of Behavior, 19, 65-72.

GamzU, E., \& Williams, D. (1973). Associative factors underlying the pigeon's key pecking in autoshaping. Journal of the Experimental Analysis of Behavior, 19, 225-232.

Gibbon, J., Baldock, M. D., Locurto, C. M., Gold, L., \& TerRACE, H. S. (1977). Trial and intertrial durations in autoshaping. Journal of Experimental Psychology: Animal Behavior Processes, 3, 264-284.

GibBon, J., \& Balsam, P. D. (1981). Spreading association in time. In C. M. Locurto, H. S. Terrace, \& J. Gibbon (Eds.), Autoshaping and conditioning theory (pp. 219-253). New York: Academic Press.

Gibbon, J., Farrell, L., Locurto, C. M., Duncan, H. J., \& TerRACE, H. S. (1980). Partial reinforcement in autoshaping with pigeons. Animal Learning \& Behavior, 8, 45-59.

GoDDARD, M. J., \& JENKINS, H. M. (1987). Effect of signaling extra unconditioned stimuli on autoshaping. Animal Learning \& Behavior, $15,40-46$.

Hinson, J. M., Malone, J. C., McNally, K. A., \& Rowe, D. W. (1978). Effects of component length and of the transitions among com- 
ponents in multiple schedules. Journal of the Experimental Analysis of Behavior, 29, 3-16.

Jenkins, H. M., Barnes, R. A., \& Barrera, F. J. (1981). Why autoshaping depends on trial spacing. In C. M. Locurto, H. S. Terrace, \& J. Gibbon (Eds.), Autoshaping and conditioning theory (pp. 255284). New York: Academic Press.

Jenkins, H. M., \& Lambos, W. A. (1983). Tests of two explanations of response elimination by noncontingent reinforcement. Animal Learning \& Behavior, 11, 302-308.

Lindelom, L. L., Jenkins, H. M. (1981). Responses elicited by noncontingent or negatively contingent reinforcement recover in extinction. Joumal of Experimental Psychology: Animal Behavior Processes, 7, 175-190.

MarCuCELla, H. (1976). Signaled reinforcement and multiple schedules. Journal of the Experimental Analysis of Behavior, 26, 199-206.

McSweEney, F. K. (1982). Positive and negative contrast as a function of component duration for key pecking and treadle pressing. Journal of the Experimental Analysis of Behavior, 37, 281-293.

Reilly, S., \& Schachtman, T. R. (1987). The effects of ITI fillers in autoshaping. Learning \& Motivation, 18, 202-219.

Rescorla, R. A. (1968). Probability of shock in the presence and absence of the CS in fear conditioning. Journal of Comparative \& Physiological Psychology, 66, 1-5.

RescorLa, R. A. (1989). Redundant treatments of neutral and excitatory stimuli in autoshaping. Journal of Experimental Psychology: Animal Behavior Processes, 15, 212-223.

Robisns, S. J., RescoRla, R. A. (1989). The role of signaled periods of nonreinforcement in responding on a random schedule in autoshaping. Animal Learning \& Behavior, 17, 304-310.

Schachtman, T. R., \& Reilly, S. (1987). The role of local context in autoshaping. Learning \& Motivation, 18, 343-355.

Shimp, C. P., \& WheAtley, K. L. (1971). Matching to relative reinforcement frequency in multiple schedules with a short component duration. Journal of the Experimental Analysis of Behavior, 15, 205-210.

Terrace, H. S., Gibbon, J., Farrell, L., \& Baldock, M. D. (1975).
Temporal factors influencing the acquisition and maintenance of an autoshaped keypeck. Animal Learning \& Behavior, 3, 53-62.

TomiE, A. (1981). Effects of unpredictable food on the subsequent acquisition of autoshaping: Analysis of the context blocking hypothesis. In C. M. Locurto, H. S. Terrace, \& J. Gibbon (Eds.), Autoshaping and conditioning theory (pp. 181-215). New York: Academic Press.

TOMIE, A. (1985). Effects of test context on the acquisition of autoshaping to a formerly random keylight or a formerly contextual keylight. In P. D. Balsam \& A. Tomie (Eds.), Context and learning (pp. 57-72). Hillsdale, NJ: Erlbaum.

Tomie, A., Murphy, A. L., Fath, S., \& Jackson, R. L. (1980). Retardation of autoshaping following pretraining with unpredictable food: Effects of changing the context between pretraining and testing. Learning \& Motivation, 11, 117-134.

Williams, B. A. (1979). Contrast, component duration and the following schedule of reinforcement. Journal of Experimental Psychology: Animal Behavior Processes, 5, 379-396.

WILLIAMS, B. A. (1980). Contrast, signaled reinforcement, and the relative law of effect. American Journal of Psychology, 93, 617-629.

Williams, B. A. (1981a). The following schedule of reinforcement as a fundamental determinant of steady state contrast in multiple schedules. Journal of the Experimental Analysis of Behavior, 35, 293-310.

WILLIAMS, B. A. (1981b). Invariance in reinforcements to acquisition, with implications for the theory of inhibition. Behaviour Analysis Letters, 1, 73-80.

Williams, B. A. (1983). Another look at contrast in multiple schedules. Journal of the Experimental Analysis of Behavior, 39, 345-384

Williams, B. A. (1989). Component duration effects in multiple schedules. Animal Learning \& Behavior, 17, 223-233.

Wilton, R. N., \& Clements, R. O. (1971). Behavioral contrast as a function of the duration of an immediately preceding period of extinction. Journal of the Experimental Analysis of Behavior, 16, 425-428.

(Manuscript received December 11, 1990; revision accepted for publication February 17, 1993.) 